\title{
The Association Between Pre-Diabetes With Body Mass Index and Marital Status in an Iranian Urban Population
}

\author{
Karamatollah Rahmanian ${ }^{1}$, Mohammad Shojaei ${ }^{2}$, Abdolreza Sotoodeh Jahromi ${ }^{2}$ \& Abdolhossein Madani ${ }^{3}$ \\ ${ }^{1}$ Research Center for Social Determinants of Health, Jahom University of Medical Sciences, Jahrom, Iran \\ ${ }^{2}$ Research Center for Non-Communicable Diseases, Jahrom University of Medical Sciences, Jahrom, Iran \\ ${ }^{3}$ Research Center for Social Determinants of Health promotion, Hormozgan University of Medical Sciences, \\ Bandarabbas, Iran
}

Correspondence: Abdolreza Sotoodeh Jahromi, Research Center for Non-Communicable Diseases, Jahrom University of Medical Sciences, Jahrom, Iran. Tel: 98-715-434-1501. E-mail: sotoodehj2002@yahoo.com

Received: May 18, 2015 Accepted: June 23, 2015 Online Published: July 30, 2015

doi:10.5539/gjhs.v8n4p95 URL: http://dx.doi.org/10.5539/gjhs.v8n4p95

\begin{abstract}
Pre-diabetes increased the development of diabetes mellitus (type 2). The aim of study was to determine the association of body weight, education and marital status with pre-diabetes in an Iranian urban population.A sample of 788 subjects ( 360 men and 428women) between the ages 30-85 years participated in our study and anthropometric measurements, educational level and fasting blood sugar of participants were recorded. The $t$ and Chi square tests were used for continuous and categorical variables. The association of age, BMI categories, educational level and marital status to pre-diabetes was assessed by estimating the odds ratio. A $p$-value $\leq 0.05$ were considered significant. The analysis was done using SPSS version 11.5. Our study showed that pre-diabetic subjects were older and low educated than normoglycemic subjects. Mean BMI and educational level were associated to pre-diabetes only in women. The odds of being pre-diabetes also were higher in obese women than in normal BMI women. No relationship was found between education and marital status with pre-diabetes in both men and women. Based on our finding, it is possible that advancing age and obesity has increased in pre-diabetes. This highlights the importance of population based survey to monitor blood glucose for effective prevention and control.
\end{abstract}

Keywords: prediabetes, body mass index, education, marital status

\section{Introduction}

Type 2 of DM (T2DM) is a most important public health crisis with a rising prevalence worldwide (Passa, 2002), because it is a common condition associated with increased morbidity and mortality (1998). The prevalence of T2DM is wide-ranging, from $1.2 \%$ to $14.6 \%$ in Asia (Azizi et al., 2003). A health survey that carried out during 2005 in Iran, used 89,400 subjects between 15-64 years old from the population of all province (Esteghamati et al., 2008), indicated that $7.7 \%$ of participants suffered from T2DM. In Iran, the prevalence of DM increased from $7.7 \%$ in 2005 to $8.7 \%$ in 2007 (Esteghamati et al. 2010). This rapidly-growing prevalence among developing countries is attributed to the urbanization (Al-Moosa et al., 2006; Shetty \& Schmidhuber, 2006). Urbanization (Mbanya et al., 2010), prediabetes, older age and abdominal obesity (Kufe et al., n.d.), physical inactivity, positive family history of diabetes, hypertension and dyslipidemia increased the risk of diabetes (Nuhoğlu et al., 2015).

Persons with pre-diabetes have a 20-30\% risk for growth of diabetes after 5-10 years (Meigs et al., 2003). In a study in Iran, the incidence of diabetes mellitus was $13.1 \%$ in persons with impaired fasting glucose (IGT) during 4 years (Hadaegh et al., 2005). Also, impaired fasting glucose or pre-diabetes increased the vrisk of cardiovascular disease (Levitzky et al., 2008).

According to result of studies, prediabetes associated with some factors. In some studies suggested that the obesity was associated with pre-diabetes (Hosler, 2009, Abtahi et al., 2010). In one study was shown that higher education was a risk of IGT only in women (Rathmann et al., 2005). Adversely, pre-diabetic subjects were low educated in compared to the control group (Javed et al., 2011). But other studies were found no significant association between education and IGT (Ko et al., 2001). Also in study was done in northeast of Iran by logistic 
regression analysis, reported that the IFG was not related to education and marital status (Azimi-Nezhad, Ghayour-Mobarhan et al., 2008).

Our study was done to assess the body weight, education and marital status relationship to pre-diabetic condition.

\section{Materials and Methods}

\subsection{Study Area}

In our cross sectional descriptive study, at the start, a multistage random sample of 892 subjects, aged $\geq 30$ years was generated from Jahrom, Fars province at Southern Iran. Jahrom includes ten urban health centers that in each center, subjects were selected using the probabilities proportional to their region population.

From all participants was obtained signed informed consent and ethical approval was obtained from the Ethics Committee of the University of Jahrom. Pregnant women or participants with renal and hepatic disease were also excluded. Anthropometric measurement in accord with the standard procedures was measured by physician. Education was classified into high (university), medium (secondary or high school) and low (primary school or illiterate). Marital status was classified into three groups; married (the just way for couples to live together in Iran is by marriage), single (those who had never been married), and divorced and widowed.

\subsection{Instruments and Measurements}

\subsubsection{Anthropometry}

Body weight was measured using Seca (Japan) to the near $0.1 \mathrm{~kg}$ with the participants wearing light clothing and without shoes. Height was measured to the adjacent 0.1 centimeter using a portable stadiometer and with their heads in the Frankfort plane without shoes. Body Mass index (BMI) was calculated as weight divided by height squared $\left(\mathrm{kg} / \mathrm{m}^{2}\right)$.

\subsubsection{Blood Sugar}

In early morning after an overnight fasting blood samples were obtained at the Peymanieh hospital and then assayed for serum sugar. A fasting blood sugar (FBS) $<100 \mathrm{mg} / \mathrm{dl}$ was considered as normal, values between 100 and $<126 \mathrm{mg} / \mathrm{dl}$ were considered as prediabetes (or Impaired Fasting Glucose, IFG) in persons who were not on hypoglycemic medications (2003).

\subsection{Statistical Analysis}

One hundred and four persons were diabetic, thus 788 persons used for the analysis presented in this paper. For statistical analysis the BMI $\left(\mathrm{kg} / \mathrm{m}^{2}\right)$ was classified into three categories: normal weight $<25$, over-weight $25.0-29.9$ and obese $\geq 30.0 \mathrm{~kg} / \mathrm{m}^{2}$ (2000). To define the characteristics of subjects, descriptive statistics was used.

The $t$ and Chi square tests were used for continuous and categorical variables. The association of age, BMI categories, educational level and marital status to pre-diabetes was assessed by estimating the odds ratio. A $p$-value $\leq 0.05$ were considered significant. The analysis was done using SPSS version 11.5.

\section{Results}

Our study was showed that the pre-diabetic subjects were significantly low educated than persons with normal FBS $(p=0.013)$. There was no statistically significant difference in other variables except for age $(p<0.001)$ between pre-diabetic and normoglycemic subjects (Table 1). Therefore, pre-diabetic subjects were about 7 years older than normoglycemic subjects.

Mean age was higher in pre-diabetic subjects than in subjects with normal FBS in both male and female (Table 2). There is a significant association of pre-diabetes with BMI groups only in female. In women, pre-diabetes was significantly associated with education. Therefore, the prevalence of low education was higher in pre-diabetic women than in women with normal FBS. Marital status and education were not association with pre-diabetes in men.

In logistic regression analysis, the risk of pre-diabetes increased with advancing age in both women and men (Table 3). Obesity was significantly associated with increased risk of pre-diabetes only in women. No statistically significant association was found between pre-diabetes and marriage and education in both women and men. 
Table 1. Descriptive characteristics of normoglycemic and pre-diabetic participants $(n=788)$

\begin{tabular}{|c|c|c|c|c|c|}
\hline & \multirow{2}{*}{\multicolumn{2}{|c|}{$\begin{array}{l}\text { Normal FBS }(\mathrm{n}=648) \\
\text { Continuous variables }\end{array}$}} & \multicolumn{2}{|c|}{ Pre-diabetes $(n=140)$} & \multirow[b]{3}{*}{ p-value } \\
\hline & & & & & \\
\hline & Mean & SD & Mean & SD & \\
\hline Age (years) & 47.8 & 13.6 & 54.7 & 13.6 & $<0.001$ \\
\hline \multirow[t]{3}{*}{ Body Mass Index $\left(\mathrm{kg} / \mathrm{m}^{2}\right)$} & 26.1 & 4.4 & 26.6 & 4.3 & 0.25 \\
\hline & \multicolumn{2}{|c|}{ Categorical variables } & & & \\
\hline & Number & $\%$ & Number & $\%$ & \\
\hline Sex & & & & & 0.192 \\
\hline Male & 289 & 44.6 & 71 & 50.7 & \\
\hline Female & 359 & 55.4 & 69 & 49.3 & \\
\hline BMI categories & & & & & 0.331 \\
\hline Normal weight & 265 & 41 & 48 & 34.3 & \\
\hline Overweight & 271 & 41.9 & 64 & 45.7 & \\
\hline Obese & 111 & 17.1 & 28 & 20 & \\
\hline Marital status & & & & & 0.211 \\
\hline Divorced or widowed & 36 & 5.6 & 12 & 8.9 & \\
\hline Single & 28 & 4.3 & 3 & 2.1 & \\
\hline Married & 548 & 90.1 & 125 & 89.3 & \\
\hline Education & & & & & 0.013 \\
\hline Low & 256 & 39.5 & 79 & 50.0 & \\
\hline Medium & 274 & 42.3 & 57 & 40.7 & \\
\hline High & 118 & 18.2 & 13 & 9.3 & \\
\hline
\end{tabular}

SD-Standard deviation.

Table 2. Association of anthropometric parameters, education and marital status with pre-diabetes between male and female

\begin{tabular}{|c|c|c|c|c|c|c|c|c|c|c|}
\hline \multirow[t]{2}{*}{ variables } & \multicolumn{5}{|c|}{ Male $(n=360)$} & \multicolumn{5}{|c|}{ Female $(n=428)$} \\
\hline & \multicolumn{2}{|l|}{ Normal } & \multicolumn{2}{|c|}{ Pre-diabetes } & \multirow[t]{3}{*}{$\mathrm{p}$} & \multicolumn{2}{|l|}{ Normal } & \multicolumn{2}{|c|}{ Pre-diabetes } & \multirow[t]{3}{*}{$\mathrm{p}$} \\
\hline Continuous vari & & & & & & & & & & \\
\hline & Mean & SD & Mean & SD & & Mean & SD & Mean & SD & \\
\hline Age, year & 50.1 & 13.9 & 55.6 & 13.5 & 0.002 & 46 & 11.9 & 53.7 & 13.7 & $<0.001$ \\
\hline BMI $\left(\mathrm{kg} / \mathrm{m}^{2}\right)$ & 24.8 & 4 & 24.9 & 3.7 & 0.858 & 27.2 & 4.5 & 28.3 & 4.2 & 0.049 \\
\hline \multicolumn{11}{|c|}{ Categorical variables } \\
\hline & Number & $\%$ & Number & $\%$ & & Number & $\%$ & Number & $\%$ & \\
\hline BMI categories & & & & & 0.156 & & & & & 0.100 \\
\hline $\begin{array}{l}\text { Normal } \\
\text { weight }\end{array}$ & 152 & 52.8 & 32 & 45.1 & & 113 & 31.5 & 16 & 23.2 & \\
\hline Overweight & 108 & 37.5 & 35 & 49.3 & & 163 & 45.4 & 29 & 42 & \\
\hline Obese & 28 & 9.7 & 4 & 5.6 & & 83 & 23.1 & 24 & 34.8 & \\
\hline Marital status & & & & & 0.920 & & & & & 0.494 \\
\hline Divorced, & 13 & 4.5 & 3 & 4.2 & & 51 & 14.2 & 12 & 17.8 & \\
\hline
\end{tabular}




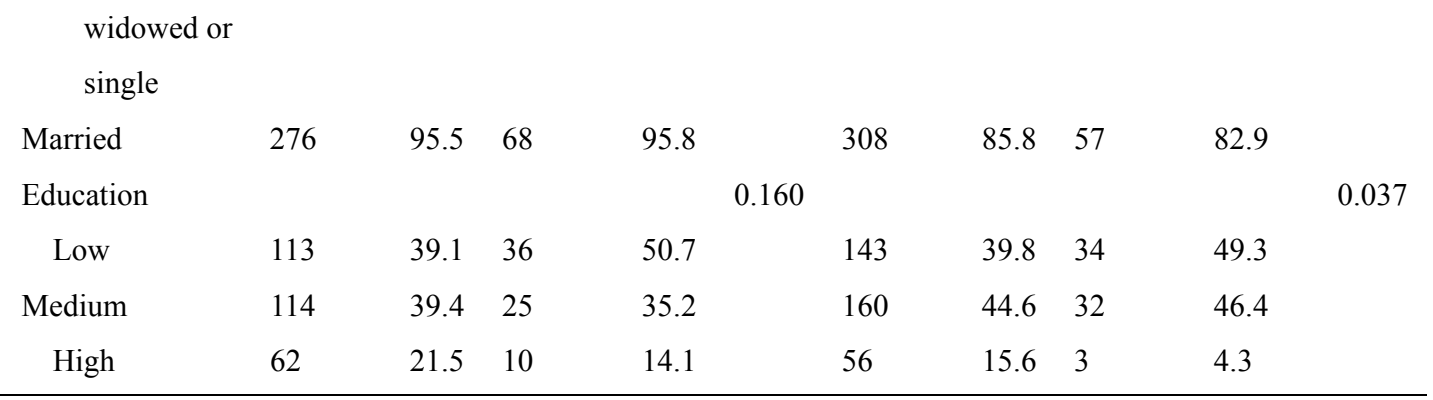

SD: Standard Deviation; yr: year.

Table 3. Determinants of pre-diabetes vs. normal fasting blood sugar from Binary logistic regression model

\begin{tabular}{|c|c|c|c|c|c|c|c|}
\hline \multirow[b]{2}{*}{ variables } & & \multicolumn{3}{|l|}{ Men } & \multicolumn{3}{|c|}{ Women } \\
\hline & & OR & CI $95 \%$ & $\mathrm{p}$ & OR & CI 95\% & $\mathrm{p}$ \\
\hline Age, year & & 1.02 & $1.01-1.07$ & 0.002 & 1.05 & $1.03-1.08$ & $<0.001$ \\
\hline $\begin{array}{l}\text { BMI group,(normal } \\
\text { reference) }\end{array}$ & wt, & & & & & & \\
\hline Overweight & & 1.68 & $0.97-2.92$ & 0.065 & 1.30 & $0.66-2.59$ & 0.442 \\
\hline Obese & & 0.78 & $0.25-2.41$ & 0.668 & 2.34 & $1.13-4.85$ & 0.022 \\
\hline $\begin{array}{l}\text { Educational level } \\
\text { reference) }\end{array}$ & (low, & & & & & & \\
\hline Medium & & 1.54 & $0.68-3.46$ & 0.297 & 3.23 & $0.93-11.15$ & 0.064 \\
\hline High & & 1.61 & $0.70-3.70$ & 0.261 & 1.76 & $0.47-6.50$ & 0.394 \\
\hline Marital status & & 1.15 & $0.29-4.46$ & 0.834 & 0.87 & $0.40-1.89$ & 0.734 \\
\hline
\end{tabular}

Variables entered on step 1: Age, marital status, Education, BMI groups. CI: Confidence Interval; OR: Odds Ratio.

\section{Discussion}

Pre-diabetes prevalence increased with raising BMI only in women. Also, Pre-diabetic prevalence inversely associated with educational level in both men and women. However with logistic regression, no relationship was found between education and marital status with pre-diabetes in both women and men.

In this study, the pre-diabetes was associated to BMI groups in the women. Similarly, Snodgrass et al suggested that fasting glucose was positively associated with BMI only in women (Snodgrass et al., 2010).Also, Bosi et al(Bosi, Carvalho et al. 2009) and Chin and Lin (Chen \& Lin, 2010) reported the association between BMI and pre-diabetes. Other studies also found the positive relationship between BMI and pre-diabetes (Cao et al., 2010; Anjana et al., 2011). But, in study conducted by Lee et al (2011) and Gupta et al. (2008), there was no significant difference between pre-diabetes and BMI.

In our study pre-diabetes was not related to education in both sexes. Similarly, in previous studies among Hong Kong Chinese (Ko et al., 2001) and in Iran (Azimi-Nezhad et al., 2008), no significant relationship between education and impaired glucose tolerance (IGT) was found. Also, in another study, the education was not related to 2 hour glucose tolerance in subjects aged 35-74 years (Metcalf et al., 2008). Adversely, in the KORA survey 2000, among subjects aged 55-74 years, higher education was significantly associated with an increased risk of IGT in women (Rathmann et al., 2005). Also, in a study conducted in Australia, lower educated men had higher FBS and 2 hour glucose (Kavanagh et al., 2010).

In our study, the association of marital status with FBS or pre-diabetes was not found. In one study conducted in north of Iran, similar result was reported. In a Cohort study (Poljicanin et al., 2012), incident diabetes was related to being married ( $\mathrm{OR}=1.57,95 \% \mathrm{CI}$ : $1.08-2.28)$.

The present study may be limited by impending risk factors or confounders which were not accounted for in the analysis. Dietary and life style behavioral risk factors such as habitual physical activity could be some limitations 
that restricted our scientific contribution to the area.

Based on our finding, it is possible that advancing age and obesity has increased in pre-diabetes. This highlights the importance of population based survey to monitor blood glucose for effective prevention and control.

\section{Abbreviations}

BMI; Body mass index, FBS; Fasting blood sugar, IFG; Impaired fasting glucose, IGT; Impaired glucose tolerance.

\section{Competing Interests}

The authors declare that they have no competing interests.

\section{Acknowledgements}

We would like to thank participants. We are also grateful to Jahrom University of Medical Sciences for financial support of this study.

\section{References}

Anonymous. (1998). "Economic consequences of diabetes mellitus in the US in 1997." Diabetes care 21: 269-309.

Anonymous. (2000). "World Health Organisation. Obesity: preventing and managing the global epidemic. Geneva: World Health Organisation."

(2003). The Expert Committee on the diagnosis and classification of diabetes mellitus: Follow-up report on the diagnosis of diabetes mellitus. Diabetes Care, 26, 3160-3167. http://dx.doi.org/10.2337/diacare.26.11.3160

Abtahi, F., Naghshzan, A., Zibaeenezhad, M. J., Heydari, S. T., Khosropanah, S., Zamirian, M., ... Moaref, A. R. (2010). The Relationship between Body Mass Index and Pre-Diabetes In Teachers Residing in Shiraz-Iran 2009. Iranian Cardiovasc Res J, 4(3), 112-117.

Al-Moosa, S., Allin, S., Jemiai, N., Al-Lawati, J., \& Mossialos, E. (2006). Diabetes and urbanization in the Omani population: an analysis of national survey data. Popul Health Metr, 4, 5. http://dx.doi.org/10.1186/1478-7954-4-5

Anjana, R. M., Pradeepa, R., Deepa, M., Datta, M., Sudha, V., Unnikrishnan, R., ... Mohan, V. (2011). Prevalence of diabetes and prediabetes (impaired fasting glucose and/or impaired glucose tolerance) in urban and rural India: Phase I results of the Indian Council of Medical Research-INdia DIABetes (ICMR-INDIAB) study. Diabetologia, 30, 30. http://dx.doi.org/10.1007/s00125-011-2291-5

Azimi-Nezhad, M., Ghayour-Mobarhan, M. P. M. R., Safarian, M., Esmaeili, H., Parizadeh, S. M. J., Khodaee, G., ... Ferns, G. (2008). Prevalence of type 2 diabetes mellitus in Iran and its relationship with gender, urbanisation, education, marital status and occupation. Singapore Med J, 49(7), 571-576.

Azizi, F., Guoya, M. M., Vazirian, P., Dolatshati, P., \& Habbibian, S. (2003). Screening for type 2 diabetes in the Iranian national programme: a preliminary report. East Mediterr Health J, 9, 1122-1127.

Bosi, P. L., Carvalho, A. M., Contrera, D., Casale, G., Pereira, M. A., Gronner, M. F., ... Leal, A. M. (2009). Prevalence of diabetes and impaired glucose tolerance in the urban population of 30 to 79 years of the city of São Carlos, São Paulo. Arq Bras Endocrinol Metabol, 53(6), 726-732. http://dx.doi.org/10.1590/S0004-27302009000600006

Cao, Y., Xue, Y. M., Li, C. Z., Zhang, M. L., Gao, F., Xie, C. H., ... Fu, X. J. (2010). Epidemiological investigation of diabetes and prediabetes in community residents in the suburbs of Guangzhou. Nan Fang Yi Ке Dа Хие Хие Вао. 30(9), 2122-2124.

Chen, S. F., \& Lin, C. C. (2010). The predictors of adopting a health-promoting lifestyle among work site adults with prediabetes. J Clin Nurs., 19(19-20), 2713-2719. http://dx.doi.org/10.1111/j.1365-2702.2010.03320.x

Esteghamati, A., Ashraf, H., Khalilzadeh, O., Rashidi, A., Mohammad, K., Asgari, F., \& Abbasi, M. (2010). Trends of diabetes according to body mass index levels in Iran: results of the national Surveys of Risk Factors of Non-Communicable Diseases (1999-2007). Diabet Med, 27(11), 1233-1240. http://dx.doi.org/10.1111/j.1464-5491.2010.03103.x

Esteghamati, A., Gouya, M. M., Abbasi, M., Delavari, A., Alikhani, S., Alaedini, F., ... Gregg, E. W. (2008). Prevalence of Diabetes and Impaired Fasting Glucose in the Adult Population of Iran: National Survey of Risk Factors for Non-Communicable Diseases of Iran. Diabetes Care, 31(1), 96-98. 
http://dx.doi.org/10.2337/dc07-0959

Gupta, A. K., Greenway, F. L., Cornelissen, G., Pan, W., \& Halberg, F. (2008). Prediabetes is associated with abnormal circadian blood pressure variability. $J$ Hum Hypertens. 22(9), 627-633. http://dx.doi.org/10.1038/jhh.2008.32

Hadaegh, F., Harati, H., \& Azizi, F. (2005). The effect of impaired fasting Glucose and impaired Glucose tolerance in prediction of incident type 2 diabetes: Tehran Lipid and Glucose Study. Iranian Journal of Endocrinology \& Metabolism, 28(7), 293-300.

Hosler, A. S. (2009). Prevalence of Self-Reported Prediabetes Among Adults Participating in a Community-Based Health Awareness Program, New York State. Prev Chronic Dis, 6(2), 1-10.

Javed, F., Al-Askar, M., Al-Rasheed, A., Babay, N., Galindo-Moreno, P., \& Al-Hezaimi, K. (2011). Comparison of Self-Perceived Oral Health, Periodontal Inflammatory Conditions and Socioeconomic Status in Individuals With and Without Prediabetes. Am J Med Sci, $16, \quad 16$. http://dx.doi.org/10.1097/MAJ.0b013e31823650a7

Kavanagh, A., Bentley, R. J., Turrell, G., Shaw, J., Dunstan, D., \& Subramanian, S. V. (2010). Socioeconomic position, gender, health behaviours and biomarkers of cardiovascular disease and diabetes. Soc Sci Med. 71(6), 1150-1160. http://dx.doi.org/10.1016/j.socscimed.2010.05.038

Ko, G. T. C., Chan, C. N., Yeung, V. T. F., Chow, C. C., Tsang, L. W. W., \& Cockram, C. S. (2001). A low socio-economic status is an additional risk factor for glucose intolerance in high risk Hong Kong Chinese. Eur J Epidemiol, 17, 289-295. http://dx.doi.org/10.1023/A:1017935707807

Kufe, C. N., Klipstein-Grobusch, K., Leopold, F., Assah, F., Ngufor, G., Mbeh, G., Mbanya, V. N., \& Mbanya, J. C. (n.d.) Risk factors of impaired fasting glucose and type 2 diabetes in Yaoundé, Cameroon: a cross sectional study. BMC Public Health. http://dx.doi.org/10.1186/s12889-015-1413-2(15): 1413-1412.

Lee, J. E., Jung, S. C., Jung, G. H., Ha, S. W., Kim, B. W., Chae, S. C., ... Kim, J. G. (2011). Prevalence of Diabetes Mellitus and Prediabetes in Dalseong-gun, Daegu City, Korea. Diabetes Metab J., 35(3), $255-263$. http://dx.doi.org/10.4093/dmj.2011.35.3.255

Levitzky, Y. S., Pencina, M. J., D'Agostino, R. B., Meigs, J. B., Murabito, J. M., Vasan, R. S. and et al (2008). Impact of Impaired Fasting Glucose on Cardiovascular Disease. J Am Coll Cardiol, 51, 264-270. http://dx.doi.org/10.1016/j.jacc.2007.09.038

Mbanya, J. C., Motala, A. A., Sobngwi, E., Assah, F. K., \& Enoru, S. T. (2010). Diabetes in sub-Saharan Africa. Lancet, 375(9733), 2254-2266. http://dx.doi.org/10.1016/S0140-6736(10)60550-8

Meigs, J. B., Muller, D. C., Nathan, D. M., Blake, D. R., \& Andres, R. (2003). The natural history of progression from normal glucose tolerance to type 2 diabetes in the Baltimore longitudinal study of aging. Diabetes, 52, 1475-1484. http://dx.doi.org/10.2337/diabetes.52.6.1475

Metcalf, P. A., Scragg, R. R., Schaaf, D., Dyall, L., Black P. N., \& Jackson, R. T. (2008). Comparison of different markers of socioeconomic status with cardiovascular disease and diabetes risk factors in the Diabetes, Heart and Health Survey. NZ Med J., 121(1269), 45-56.

Nuhoğlu, İ., Erem, C., Ersöz, H. Ö., Koçak, M., \& Civan, N. (2015). The prevalence of diabetes and associated risk factors among adult population in a Turkish population (Trabzon city). Endocrine Abstracts, 37, EP365| http://dx.doi.org/310.1530/endoabs.1537.EP1365.

Passa, P. (2002). Diabetes trends in Europe. Diabetes Metab Res Rev, 18(suppl 3), S3-8. http://dx.doi.org/10.1002/dmrr.276

Poljicanin, T., Sekerija, M., Boras, J., Kolaric, B., Vuletic, S., \& Metelko, Z. (2012). Cumulative incidence of self-reported diabetes in Croatian adult population in relation to socioeconomic status and lifestyle habits. Coll Antropol, 1, 41-46. http://dx.doi.org/10.5671/ca.2012361s.41

Rathmann, W., Haastert, B., Icks, A., Giani, G., Holle, R., Meisinger, C., \& Mielck, A. (2005). Sex differences in the associations of socioeconomic status with undiagnosed diabetes mellitus and impaired glucose tolerance in the elderly population: the KORA Survey 2000. Eur J Public Health. 15(6), 627-633. http://dx.doi.org/10.1093/eurpub/cki037

Shetty, P., \& Schmidhuber, J. (2006). Introductory lecture the epidemiology and determinants of obesity in developed and developing countries. Int $J$ Vitam Nutr Res, 76, 157-162. http://dx.doi.org/10.1024/0300-9831.76.4.157 
Snodgrass, J. J., Leonard, W. R., Tarskaia, L. A., Egorova, A. G., Maharova, N. V., Pinigina, I. A., ... Romanova, A. N. (2010). Impaired Fasting Glucose and Metabolic Syndrom in an Indigenous Siberian Population. Int $J$ Circumpolar Health, 69(1), 87-98. http://dx.doi.org/10.3402/ijch.v69i1.17430

\section{Copyrights}

Copyright for this article is retained by the author(s), with first publication rights granted to the journal.

This is an open-access article distributed under the terms and conditions of the Creative Commons Attribution license (http://creativecommons.org/licenses/by/3.0/). 